\title{
Failure Behavior of the Thermal Treated Granite under Triaxial Cyclic Loading-unloading Compression
}

\author{
Wen-Ling Tian ${ }^{1}$, Sheng-Qi Yang ${ }^{1}$, Jianguo Wang ${ }^{1}$, and Jin-Peng Dong ${ }^{1}$ \\ ${ }^{1}$ China University of Mining and Technology
}

August 7, 2020

\begin{abstract}
The failure behavior of thermal treated granite under triaxial tiered cyclic loading-unloading compression has a significant effect on the safe and stable operation of HLW disposal repository. Therefore, the stress-strain curves, elastic modulus, Poisson's ratio, plastic strain, dissipated energy and failure characteristic of the thermal treated granite specimens under triaxial compression were analyzed by experiment and numerical simulation. The results indicate that the elastic, Poisson's ratio, axial plastic strain, dissipated energy and accumulative AE counts slightly increase with cyclic loading at initial loading and elastic deformation stage when $\mathrm{T}=25$ and $300^{\circ} \mathrm{C}$, which means that less damage was induced by cyclic loading. However, damage occurred once cyclic loading was applied when $\mathrm{T}=600^{\circ} \mathrm{C}$. Radial strain even showed compressive characteristic in the initial stage, which indicates that grains adjustment occurred under triaxial cyclic loading-unloading compression. And, the compressive characteristic is more obvious with the increase of temperature or the decrease of confining pressure. The failure modes under triaxial cyclic loading are more complicated than that under triaxial monotonic loading, which make the shear plane rougher. Therefore, the residual strength is higher than that under monotonic loading. When $\mathrm{T}=600^{\circ} \mathrm{C}$, micro-crack continuously increases under uniaxial unloading and loading process, which result in a decrease of the peak strength under cyclic loading compared with that under monotonic loading.
\end{abstract}

Failure Behavior of the Thermal Treated Granite under Triaxial Cyclic Loading-unloading Compression Wen-Ling Tian, Sheng-Qi Yang(), Jian-Guo Wang, Jin-Peng Dong

State Key Laboratory for Geomechanics and Deep Underground Engineering, School of Mechanics and Civil Engineering, China University of Mining and Technology, Xuzhou 221116, PR China;

*To whom correspondence should be addressed.

Email: yangsqi@hotmail.com

Telephone number: +86-516-83995856

Fax: $+86-516-83995678$

Address: State Key Laboratory for Geomechanics and Deep Underground Engineering, China University of Mining and Technology, Xuzhou 221116, China.

Abstract: The failure behavior of thermal treated granite under triaxial tiered cyclic loading-unloading compression has a significant effect on the safe and stable operation of HLW disposal repository. Therefore, the stress-strain curves, elastic modulus, Poisson's ratio, plastic strain, dissipated energy and failure characteristic of the thermal treated granite specimens under triaxial compression were analyzed by experiment and numerical simulation. The results indicate that the elastic, Poisson's ratio, axial plastic strain, dissipated energy and accumulative AE counts slightly increase with cyclic loading at initial loading and 
elastic deformation stage when $T=25$ and $300^{\circ} \mathrm{C}$, which means that less damage was induced by cyclic loading. However, damage occurred once cyclic loading was applied when $T=600^{\circ} \mathrm{C}$. Radial strain even showed compressive characteristic in the initial stage, which indicates that grains adjustment occurred under triaxial cyclic loading-unloading compression. And, the compressive characteristic is more obvious with the increase of temperature or the decrease of confining pressure. The failure modes under triaxial cyclic loading are more complicated than that under triaxial monotonic loading, which make the shear plane rougher. Therefore, the residual strength is higher than that under monotonic loading. When $T=600^{\circ} \mathrm{C}$, micro-crack continuously increases under uniaxial unloading and loading process, which result in a decrease of the peak strength under cyclic loading compared with that under monotonic loading.

Key words: Granite; high temperature; cyclic loading-unloading, dissipated energy, GBM

\section{Introduction}

During the excavation of the High Level nuclear Waste (HLW) disposal repository, the surrounding rock bear the periodic loading due to blasting vibration, mechanical excavation and redistribution of crustal stress. Meanwhile, in the using procedure of repository, periodic loading also formed due to mechanical vibration. The cyclic loading acts on the surrounding rock constantly, and causing a hazard to the safe and stable operation of the disposal repository. And, cyclic loading provide an effective way for better investigating rock damage and deformation characteristics (Zhou et al., 2019). The research on the mechanical behavior of granite under cyclic loading has a long history, and a series of achievements have been obtained.

Two types of cyclic loading tests are commonly used, which include fatigued and tiered cyclic loading. Fatigued loading is that loading cycled between a prescribed stresses interval, and it is widely used to evaluate the stability of tunnel under long-term dynamic loading. Under conditions of fatigued loading, damage of rock can be divided into three stages: initial damage, constant-velocity damage, and accelerated damage (He et al., 2019). Fatigued life increases as a power-law function with maximum stress decreasing, and the maximum stress also significantly affects the fatigued life (Momeni et al., 2015). And, the fatigued life of specimen subjected to discontinuous cyclic compression decreased sharply in comparison with conventional fatigued tests (Fan et al., 2019). Loading frequency affects the fatigued strength as well as the deformation of rock specimen (Arora et al., 2019). The level of confining pressure had a significant influence on the cyclic dynamic deformation and fatigued damage evolution of the rock samples (Liu and He, 2012). The stress lower limit can significantly affect the evolution of irreversible deformation, and the elastic modulus and Poisson's ratio also increased significantly when the stress lower limit increased stepwise (Peng et al. 2019). The stress corresponding to the transition from volumetric compaction to volumetric dilation may be considered to be the threshold for fatigued failure (Wang et al., 2015). The crack propagation threshold appeared to gradually increase with each cyclic loading when the samples loading is beyond the crack propagation threshold (Ghazvinian and Diederichs, 2015).

However, in engineering practices, cyclic stress are not always of equal amplitude. Therefore, tiered cyclic loading-unloading should be investigated. Tiered cyclic loading is a special form of cyclic loading, where stress amplitude increases from one cycle to next cycle. Kaiser effect is that the absence of AE activity at stress levels less than the previously maximum axial stress (Kaiser, 1953), which can reflect the damage progress under cyclic loading (Rao and Ramana, 1992; Li and Nordlund, 1993). Felicity effect is the phenomenon that AE signal is more obvious before reaching the previous maximum axial stress, and Felicity ratio decreases with the increase of cyclic number (Meng et al., 2016, 2018). AE signal can also reflect the crack propagation under unloading process, under lower stress level, no AE signal can be monitored after unloading; however, AE signal can be monitored in the whole unloading process under higher stress level (Jiang et al., 2017). The propagation of crack can be divided into different stages, and the differences can be successfully identified according to the $\mathrm{AE}$ hits and $\mathrm{AE}$ events (Zhou et al., 2019). X-ray micro-CT, P-wave and photomicrographs were also used to investigate the effect of cyclic loading, and more branch crack can be observed in the specimen under cyclic loading than monotonic loading (Yang et al., 2015, 2017a). The development of the damage state can be briefly divided into three stages, which is as follows: constant gain rate during the pre-peak stage, increasing gain rate during the strain softening stage, and constant gain rate during the 
residual stage (Xiong et al., 2019).

Granite, as an excellent medium for high-level nuclear waste disposition, has lower permeability and better integrity (Yang et al., 2017b; Zhao et al., 2015). During the decay of radionuclides, a large amount of heat is released, which lead to transformation of granite mechanical behavior (Chen et al., 2017). Therefore, the failure behavior of thermal treated granite under triaxial tiered cyclic loading-unloading compression should be investigated to insure the safe and stable operation of HLW disposal repository. And, the evolution of elastic modulus, Poisson's ratio and dissipated energy were analyzed in this work.

\section{Experimental methodology}

\subsection{Granite material}

The granite used in this research was collected from Rizhao city in Shandong province, China. According to the results of X-ray diffraction (XRD), the minerals in the granite are feldspar (59.85\%), biotite $(21.56 \%)$, quartz $(11.12 \%)$, amphibole $(6 \%)$, chlorite $(1.01 \%)$ and dolomite $(0.46 \%)$. This granite has a crystalline and blocky structure with a connected porosity of $0.828 \%$ (Yang et al., 2017b). The average density of the tested granite at room temperature is approximately $2594 \mathrm{~kg} / \mathrm{m}^{3}$, and its P-wave velocity is about 4200 $\mathrm{m} / \mathrm{s}$. Before beginning the triaxial cyclic loading-unloading tests, the granite specimens were first placed in the furnace and the heating rate was set as $5 \mathrm{degC} / \mathrm{min}$ to minimize thermal shocks. The predetermined temperature was kept constant for $2 \mathrm{~h}$ to ensure uniformity in temperature across the specimen. For triaxial cyclic loading-unloading tests, the target temperatures were set as 300 and 600degC. Finally, the heated specimens were left in the furnace to cool down to the room temperature.

\subsection{Testing system and procedure}

All of the triaxial cyclic loading-unloading compression tests were performed in a RTX-4000 high-temperature and high-pressure rock triaxial testing system at the state key laboratory for geomechanics and deep underground engineering. The maximum axial loading capacity is $4000 \mathrm{kN}$, and the maximum confining pressure is $140 \mathrm{MPa}$. The triaxial tiered cyclic experiments were carried out under different confining pressure $\left(\sigma_{3}\right)$ of $0,10,20,30$ and $40 \mathrm{MPa}$, and consisted of the following three steps. First, the confining pressure was applied at a rate of $0.4 \mathrm{MPa} / \mathrm{s}$. Second, the specimens were loaded to the predetermined axial strain value at a controlled axial displacement rate of $0.04 \mathrm{~mm} / \mathrm{min}$, and then unloaded the deviatoric stress to zero at a rate of $40 \mathrm{MPa} / \mathrm{min}$ through controlling axial stress. In each subsequent cycle, the second deviatoric strain level was increased, and then unloaded it to zero again. Finally, the stress cyclic was continued in that way until the specimens enter the residual strength phase.

\section{Deformation Characteristic of Thermal Treated Granite under cyclic loading-unloading com- pression}

\subsection{Stress-strain curves}

Figure 1 illustrates the stress-strain curves of thermal treatment granite under triaxial cyclic loading compression, it is in good agreement with the stress-strain curves of granite under monotonic loading except for granite specimen when $T=600^{\circ} \mathrm{C}, \sigma_{3}=0 \mathrm{MPa}$. It can be explained that cyclic loading has a slight effect on the crack propagation of intact granite. However, when more thermal cracks were induced in rock, the cracks were easier to propagate under uniaxial cyclic loading, and make the strength of specimen decreases. Confining pressure can restrain the crack propagation, therefore cyclic loading has a slight effect on the stress-strain curves of granite specimen when $T=600^{\circ} \mathrm{C}, \sigma_{3}=40 \mathrm{MPa}$.

At initial loading at each cycle, the axial loading and unloading stress-stain curves show a concave type. It means that fissures in granite opened under unloading process, and then reclosed under loading process. After the first loading-unloading compression, the concave characteristic is not evident, which indicates that the closed fissures cannot open completely. The concave type is more obvious after the peak strength, which indicates that the fissures induced by axial stress also opened and reclosed in the cyclic loading-unloading process. The loading enter to the elastic stage with increasing axial stress, even though the macro-crack 
has been formed, there is also elastic stage after the peak strength. The loading enter to the plastic stage after the elastic stage, the plastic stage is unobvious before the peak strength, and it is more obvious with increasing cycle number after the peak strength. After the peak strength, the axial stress decreases gradually with cycle number. However, the residual strength of specimen under the cyclic loading is larger than that under monotonic loading on the whole.

\subsection{Evolution of Elastic Modulus and Poisson's ratio of thermal treated granite with Cyclic Number}

Figure 2 shows the variation of elastic modulus $(E)$ with cycle number, Young's modulus represents the slop of stress-strain curve in linear segment under loading stage (30\%-70\% of the peak strength in each cyclic loading). It is clear that elastic modulus first increases and enter a stable phase, then decreases before becoming constant again with cycle number. In the early loading stage, pre-existing fissures closed and result in the increase of elastic modulus. After that, the loading enter to the elastic stage, few crack initiate in this loading stage, and the elastic modulus remains near constant. With the increase of cycle number, more micro-cracks were induced by compression, and macro-crack formed gradually, which result in the decrease of elastic modulus. However, after the loading enter to the residual strength stage, and the elastic modulus reach to a plateau again.

Fissures pre-closed when applied confining pressure partially, and make the increasing stage of elastic modulus shorter than that under uniaxial compression. It is also clear that elastic modulus increases with the increase of confining pressure at the same cycle number, this phenomenon is more obvious in the granite specimens treated by $600^{\circ} \mathrm{C}$. After high temperature treatment, more cracks are induced, the potential for cracks to close is great, and make the elastic modulus more sensitive to confining pressure. Confining pressure also restrain crack propagation under loading process, therefore the elastic deformation stage is more obvious with the increase of confining pressure, and the decreasing rate of elastic modulus with cycle number decreases in the macro-crack formed stage. Confining pressure also increases the contact area of the macro-crack, and result in the increase of elastic modulus in the residual strength stage.

Figure 3 depicts Poisson's ratio of granite after thermal treatment under different confining pressure. Poisson's ratio represents the ratio between radial and axial strain in the elastic stage, it may be larger than 0.5 after the macro-cracks formed (not in the elastic deformation stage). Poisson's ratio remains near constant in the initial stage, then increases rapidly, and decreases slightly before entering a stable phase again with cycle number on the whole. The slight decreases of Poisson's ratio are also obtained by Xiong et al (2019). It indicates that there is few crack induced by loading in the initial stage, and the radial strain is not evident. After that, more vertical micro-cracks are formed, and it re-open in the elastic stage, which result in the expansion in radial direction. However, slippage occurred along macro-crack, and lead to the re-open for vertical micro-cracks decreases, when the loading to the residual strength stage. Therefore, Poisson's ratio slightly decreases before entering a stable phase again. Poisson's ratio of specimen under uniaxial compression is lesser than that under triaxial compression at initial loading stage when $T=25^{\circ} \mathrm{C}$ and $300^{\circ} \mathrm{C}$, as shown in Figs. 3a-b. It can be explained as that pre-existing fissure closed when applied confining pressure, and result in the decrease of potential for grain to adjustment under loading process, therefore the specimen is easier to expansion in radial direction. The splitting tensile crack is easier to initiate in specimen under uniaxial compression, and it re-open under loading process, which make the increasing rate of Poisson's ratio higher than that under triaxial compression. Confining pressure can restrain micro-cracks re-open, and Poisson's ratio decreases with increasing confining pressure on the whole.

When $T=600^{\circ} \mathrm{C}$, more thermal cracks are induced in specimen, which lead to the increases of Poisson's ratio with cycle number once applied compression as shown in Figs. 3c. Lacking confining pressure, Poisson's ratio of specimen under uniaxial compression is larger than that under triaxial compression. After macro-cracks formed, the decreasing rate of Poisson's ratio with cycle number is larger than that when $=25^{\circ} \mathrm{C}$ and $300^{\circ} \mathrm{C}$, it indicates that there are more vertical cracks in specimen when $T=600^{\circ} \mathrm{C}$.

3.3 Evolution of plastic strain of thermal treated granite specimens with axial strain

Plastic strain is the irrecoverable strain in the cyclic loading-unloading process, which can reflect the damage 
in specimen to some extent. Figure 4 illustrates the variation of axial plastic strain with the maximum axial stain $\left(\epsilon_{1 \mathrm{u}}\right)$ in each cyclic loading, it is clear that axial plastic strain non-linearly increases with the maximum axial strain on a concave type. Axial plastic strain increases gradually at the initial loading stage, and inflection point appeared. Finally, axial plastic strain near linearly increases with the maximum axial strain in each cycle at macro-crack forming and shear slippage stage. With increasing confining pressure, axial plastic strain decreases, which indicates that confining pressure can retrain the axial plastic strain to some extent. When $T=600^{\circ} \mathrm{C}$, axial plastic strain near linear increases with the maximum axial strain in each cycle, which indicates that damage occurred once applied loading. In conclusion, the damage evolution is influenced by the initial damage state and confining pressure.

Figure 5 shows the variation of radial plastic strain with the maximum axial strain, it can be seen that the radial strain is smaller in the initial stage, and even compressive characteristic appeared, this phenomenon was also obtained by Xiong et al. (2019). The partial enlarged drawing of the radial plastic strain is shown in Fig. 5d, the compressive characteristic is more obvious with increasing temperature. It indicates that the grain adjusted under triaxial cyclic loading-unloading compression when there are micro-cracks in specimen. The compressive characteristic is more unobvious with increasing of confining pressure, it may be because micro-crack pre-closed when applied confining pressure. And then radial plastic strain shows expansion characteristic with increasing the maximum axial strain in each cycle. It can be also seen that the reversed point from compression to expansion is backward with increasing confining, it indicates that confining pressure restrain radial plastic strain.

\section{Evolution of energy}

The deformation and failure of rock are always accompanied by energy dissipation (Xie et al., 2005), and some researcher hold the view that the energy dissipation can accurately reflect the change in the mechanical properties of rocks (Ye et al., 2001). Assuming no heat exchange between the sample and external, the work done by the external load on the rock specimen $(U)$ is transformed into the elastic strain energy $\left(U_{\text {e }}\right)$ and dissipated energy $\left(U_{\mathrm{d}}\right)$, and the energy equation can be expressed as

$U=U_{\mathrm{e}}+U_{\mathrm{d}}$

The calculation energy under triaxial cyclic loading process is shown in Fig. 6 . The elastic strain energy $(U$ e) contained axial strain energy () and radial strain energy (), as shown in Eq. (3). is the area between the unloading axial stress-strain curve and the axial strain axis, is the area the unloading confining pressurestrain curve and the radial strain axis. The dissipated energy $\left(U_{\mathrm{d}}\right)$ is the difference between the input energy $(U)$ and elastic strain energy $\left(U_{\mathrm{e}}\right)$, and $U_{\mathrm{d}}$ also contained axial dissipated energy () and radial dissipated energy (), as shown in Fig. 6.

where is input axial energy, is input radial energy. is unloading axial stress, and are unloading axial and radial strain, respectively.

Figure 7 illustrates the variation of axial input energy, radial input energy, axial strain energy, radial strain energy, dissipated energy of granite specimens under triaxial cyclic loading with cycle number $\left(\sigma_{3}=20 \mathrm{MPa}\right)$. It is clear that the radial input and elastic strain energy is relatively small compared with axial input energy, axial elastic strain energy and dissipated energy. Therefore, we mainly discuss the axial input energy, axial elastic strain energy and dissipated energy in this paper. Before damage threshold strength, the axial input energy, axial elastic strain energy and dissipated energy non-linearly increase with cycle number. When $T=25$ and $300^{\circ} \mathrm{C}$, axial input energy almost transfer as axial strain energy. However, axial strain energy and dissipated energy are near equal when $T=600^{\circ} \mathrm{C}$, it indicates that damage occur in specimen once apply loading. This characteristic corresponds well with the axial plastic strain in Fig. 4. After the damage threshold strength, the difference between axial input and elastic strain energy increases, and the axial elastic strain energy reach to the peak at the peak strength. The increasing rate of dissipated energy increases with cycle number. After the peak strength, axial elastic strain released and macro-cracks formed, which result in the quick increase of dissipated energy. As the strength and elastic modulus of specimen decreases, the increasing ratio of axial input strain decreases gradually. When the loading enter to the residual strength 
stage, the axial elastic strain energy remains near constant, while the dissipated energy is near parallel to the axial input energy, which indicates that axial input energy almost transfer to frication energy. However, the difference between axial energy and dissipated energy increases with cycle number, and the radial input energy increases obviously when $T=600^{\circ} \mathrm{C}$. It means that the radial expansion is obvious, and a part of axial input energy transfer as radial input energy.

To investigate the effect of confining pressure on energy evolution, the variation of axial input energy, axial elastic strain energy and dissipated energy of granite specimen under triaxial cyclic loading at room temperature with cycle number is illustrated in Fig. 8. It can be seen that axial input energy and dissipated energy non-linearly increases with cycle number on S type, as shown in Figs. 8a-b. With increasing confining pressure, the axial input energy and its increasing rate increase, this characteristic is more obvious between uniaxial compression and triaxial compression when $\sigma_{3}=10 \mathrm{MPa}$. Confining pressure increases the carrying capacity of rock, and need more dissipated energy to destroy the rock, therefore when the specimen failed, the dissipated energy increase with increasing confining pressure. Confining pressure also restrain the crack initiation and propagation, therefore the variation of dissipated energy of specimen with confining is irregular before failure. The axial elastic strain energy first increases and then decreases before reaching a plateau at residual strength stage with cycle number, as shown in Fig. 8c. With increasing confining pressure, the axial elastic strain energy value, the increasing and decreasing rate increase with increasing confining pressure. It indicates the capacity to store strain energy increases with increasing confining pressure. As more strain elastic energy is stored in specimen under higher confining pressure, the specimen destroy seriously during strain elastic energy release process, which result in the increase of decreasing rate of axial elastic strain energy with increasing confining pressure. Frication force between macro-crack is larger under higher confining pressure, which results in the larger residual strength and axial elastic strain energy.

Plastic strain and dissipated energy were widely used to define the damage parameter of rock under cyclic loading (Eberhardt et al., 1999, Yang et al., 2015, Wang et al., 2018). However, the relationship between plastic strain and dissipated energy is not discussed before. Therefore, the variation of dissipated energy of granite under triaxial cyclic loading after different high temperature treatment with axial plastic strain is illustrated in Fig. 9. It can be seen that dissipated energy non-linearly increases with axial plastic strain on convex type. At initial loading stage, there is few crack in the specimen, and need more dissipated energy to initiate crack. As the axial plastic strain increase, more cracks are induced in the specimen, which make the initiation of crack easier and result in the decrease of increasing rate of dissipated energy with axial plastic strain gradually. After the macro-crack formed, energy mainly dissipate on the frictional slippage between macro-crack, which result in the linear increases of it with plastic strain. Due to more thermal cracks are induced in the specimens when $T=600^{\circ} \mathrm{C}$, the non-linear characteristic is unobvious compare with that when $T=25$ and $300^{\circ} \mathrm{C}$.

It can be also seen that the dissipated energy increases with increasing confining pressure at same axial plastic strain, it indicates that it need more energy to initiate crack under higher confining pressure. Confining pressure also increases friction between macro-crack, which result in the increase of rising rate of dissipated energy with plastic strain. With increasing temperature, more thermal cracks are induced in the specimen, and the dissipated energy is more sensitive to confining pressure.

\section{$5 \mathrm{AE}$ and Failure Characteristic}

Figure 10 illustrates the evolution of $\mathrm{AE}$ account and accumulative $\mathrm{AE}$ counts of granite specimens under cyclic loading-unloading compression, $\mathrm{AE}$ and $\mathrm{AAE}$ represent as $\mathrm{AE}$ account and accumulative $\mathrm{AE}$ counts, respectively. On the whole, AAE shows a ladder-like growth with duration time. At room temperature, weak $\mathrm{AE}$ events are monitored at the initial compaction and elastic stage. When the loading near the peak strength, accumulative AE hits thrived increases. After the peak strength, axial stress drop quickly, and violent AE events are monitored. However, the AE events decreases obviously when the loading enter to the residual strength stage, and few micro-crack initiated due to the friction between the micro-crack under cyclic loading process. Compared with Figs. 4 and 7, it can be seen that the evolution of AAE is similar to that of axial plastic strain and dissipated energy, whereas there is also difference. This may be because dissipated energy 
result in not only the plastic strain but also crack propagation. Under uniaxial compression, the coupling is insufficient between AE probe and specimen, and the AAE is lesser than that under triaxial compression.

When $T=600^{\circ} \mathrm{C}$, more thermal cracks are induced in the specimen, and lead to the carrying capacity loss under uniaxial compression. Under cyclic loading process, displacement occurred between grains with less friction, and less AE events are monitored, as shown in Fig. 10a. Confining pressure closed the thermal induced crack and increases friction between grains, therefore more AE events are monitored once applied loading. Compared with Figs. 10b and 10d, after thermal treatment, violent AE events is lesser than that at room temperature, whereas AAE is more than that at room temperature. It means that the micro-crack is easier to initiate and dispersed distribute in the specimen, and the loading process shows plastic characteristic when $T=600^{\circ} \mathrm{C}$.

Figures 11 depict the comparison of the ultimate failure model of granite after thermal treatment between triaxial monotonic and cyclic loading compression, it is clear that loading path has slight effect on the ultimate failure modes. Under uniaxial compression, the granite specimens under monotonic and cyclic loading failed with axial splitting. Under triaxial compression, the distribution of cracks under cyclic loading is more complicated than that under monotonic loading, even though the specimen failed with shear cracks. On the one hand, more energy dissipated in the granite specimens under cyclic loading, which result in more microcracks initiation. Therefore, the potential position to form macro-cracks in the specimen increases. On the other hand, the shear cracks propagated quickly under monotonic loading after the peak strength. However, the shear cracks propagated step by step under cyclic loading. The shear cracks near stop propagated under unloading process, and then it may not propagate in the original direction under loading process. Therefore, the distribution of cracks in the specimens under cyclic loading is more complicated than that under monotonic loading. This phenomenon is also obtained by Yang et al. (2015).

\section{Discussion}

From above analysis, it can be seen that loading path has slight effect on the failure modes under uniaxial compression, the specimen failed with axial splitting. However, the failure modes under triaxial cyclic loading are more complicated than that under triaxial monotonic loading. To explain this phenomenon, the cracks formed in the previous cyclic loading are regarded as the per-existing crack, and the cracks formed in this cyclic loading are regarded as new initiated crack. Figure 12 illustrates crack propagation sketch diagram of specimen containing a single fissure under triaxial compression, bold line and filament represent pre-existing and new cracks, respectively. Under uniaxial, loading tend to initiate vertical crack, thus the crack formed in previous cyclic loading is regarded as the vertical pre-existing fissure, as shown in Fig. 12a. And, the new crack initiate in the tip of fissure, then propagate in the original direction. Therefore, loading path has slight effect on the failure modes under uniaxial compression. Under triaxial compression, loading tend to induce inclined crack, thus the crack formed in pervious cyclic loading is regarded as inclined pre-existing fissure, as shown in Figs. 12b-c. And, the new crack initiate in the tip of fissure, then propagate in various type. Therefore, the failure modes under triaxial cyclic loading are more complicated than that under triaxial monotonic loading. As the failure modes are more complicated under cyclic loading-unloading compression, the shear plane is rougher, which make the residual strength higher than that under monotonic loading, as shown in Fig. 1.

To verify the above assumption, Grain Based Model $(\mathrm{GBM})$ in $\mathrm{PFC}^{2 \mathrm{D}}$ was used to simulate the triaxial cyclic loading-unloading compression of granite after thermal treatment. To generate the GBM that has a microstructure comparable to the rock specimen, the mineralogical composition should keep with the granite in this test, as shown in Table 1. As shown in Fig. 13a, after assigning particles and contact properties according to the minerals, the inter-granular parallel bonds were replaced by Smooth joint (SJ). In general, the micro-parameters used in $\mathrm{PFC}^{2 \mathrm{D}}$ have no direct relationship with the macro-properties in the rock specimen. Calibration has to be strategically carried out using a trial-and-error approach in $\mathrm{PFC}^{2 \mathrm{D}}$. In the GBM of granite specimen, four different minerals are considered, and corresponding parallel bonds and disks should be assigned with different micro-parameters. Even though the micro-parameters of four minerals cannot quantitatively reflect the mechanism of the grains, these parameters are assigned values in proportion 
to the real mineral properties suggested by Bass (1995). The micro-parameters for the numerical model of this granite are calibrated using the approach proposed by Peng et al. (2018). The peak strength obtained by simulation results are shown in Fig. 13b, it can be seen that the experimental results are generally captured by the GBM.

To accurately reflect the thermal behavior of granite containing different minerals, the thermal expansion coefficients assigned to the grains as follows: plagioclase, $8.7 \times 10^{-6} \mathrm{~K}^{-1}$; quartz, $24.3 \times 10^{-6} \mathrm{~K}^{-1}$; Amphibole, $28 \times 10^{-6} \mathrm{~K}^{-1}$; biotite, $3.0 \times 10^{-6} \mathrm{~K}^{-1}$ (Fei, 1995; Wittels, 1951). To minimize thermal shock and the development of stress fractures, the temperature of the granite specimens was assumed to change uniformly and in a sufficiently short time (Zhao, 2016, Tian et al., 2018), the temperature of the granite specimen uniformly changed by $1^{\circ} \mathrm{C}$ every step and then cycle 100 steps. The radius expansion with 1.0046 (Carpenter et al. 1998) is applied to the quartz grains when the temperature elevated to $573^{\circ} \mathrm{C}$, and the quartz particle radius shrinks with 0.9954 when the temperature decreases to $573^{\circ} \mathrm{C}$. This process can be used to simulate the phase transition of quartz. After thermal treatment, more intra-granular and inter-granular cracks were observed, the inter-granular net around each granite crystal grain was formed and made the ploy grains be isolated with each other (Zhao et al., 2008), and intra-granular crack is dominantly located in the quartz grains, as shown in Fig. 13a. The loading and unloading process simulated by GBM is similar to that in experiment, loading controlled by axial displacement and unloaded controlled by axial stress, as shown in Fig. 13a.

Figure 14 illustrates the comparison of crack propagation characteristic between cyclic and monotonic loading of granite specimens under room temperature and $40 \mathrm{MPa}$ confinement. In Fig. 14c, the serial number represents cycle number, and the serial number in Fig. 14d under monotonic loading correspond with that in Fig. 14c. From Fig. 1d and Fig. 14a, it can be seen that the stress-strain curves of granite under cyclic loading is in good agreement with that under monotonic loading before the peak strength, which means that cyclic loading has slight effect on the crack evolution of granite, and the evolution of micro-crack with axial strain agree well with each other. Due to higher confining pressure, more intra-granular cracks are observed than inter-granular cracks. Micro-cracks dispersed distribute in the specimen, and is mainly parallel to the loading direction. When loading to the peak strength, micro-cracks began to coalesce with each other, and these is also mainly parallel to the loading direction, whereas the direction of micro-cracks under cyclic loading is more complicit than that under monotonic loading. This phenomenon is accordant with that observed by experiment in this paper and that observed by Yang et al. (2015) through micro-CT, and it also verify the above assumption.

After the peak strength, the stress-strain and micro-cracks evolution curves of granite under cyclic loading deviated from these under monotonic loading. The micro-cracks began to increase under unloading process, and it also increases before the stress reach to the previous maximum stress (Felicity effect, Meng et al., 2018). At the moment, the inter-granular and intra-granular cracks of granite under cyclic loading are more than that under monotonic loading, especially for the intra-granular cracks. The macro-cracks have been formed in the specimen under cyclic loading, and the direction is more complicated. However, there is no macro-crack in the specimen under monotonic loading, and the micro-crack is mainly parallel to the loading direction. When the macro-crack has been formed, micro-cracks continuously increase under loading and unloading process, due to friction between macro-cracks. However, increasing rate of micro-crack decreases obviously. When the specimen failed, the failure model of specimen under cyclic loading is more complicated than that under monotonic loading. As the failure modes are more complicated under cyclic loading-unloading compression, the shear plane is rougher, which lead to the residual strength is higher than that under monotonic loading.

More thermal micro-cracks were induced in the specimen when $T=600^{\circ} \mathrm{C}$, and the crack evolution characteristic of specimen under cyclic loading is different from that under monotonic loading, as shown in Fig. 15a, which is accordant well with that obtained by experiment, as shown in Fig. 1c. Due to the bearing structure destroyed by high temperature, micro-crack continuously increases under unloading and loading process. Therefore, the stress-strain and micro-crack evolution curves separated with each other under cyclic and monotonic loading after the first loading. When the specimen was loaded by 5 cycles, the inter-granular cracks of specimen under cyclic loading are more than that under monotonic loading, whereas the intra-granular 
cracks near equal with each other. It indicates that inter-granular are easier to propagate than intra-granular under loading and unloading process. Due to more micro-cracks were induced under cyclic loading, the peak strength under cyclic loading is lesser than that under monotonic loading. This phenomenon can be also seen in experimental result, as shown in Fig. 1c. The micro-cracks induced by loading is lesser than that induced by thermal treatment, the direction of micro-crack is randomly, and it is slightly effected by cyclic loading process.

After the peak strength, stress decreases gradually, the stress-strain and micro-crack evolution curves under cyclic loading deviated from these under monotonic loading obviously. At this point, micro-cracks coalesced with each other, and no macro-crack formed. When the specimen failed, stress decreases quickly under monotonic loading, and more intra-granular cracks were observed than that under cyclic loading, which means that the quick decrease of stress is easier to induce intra-granular crack. At this moment, the splitting tensile macro-cracks were observed in specimens, which is accordant well with that obtained by experiment, as shown in Fig. 13a.

\section{Conclusions}

In this work, triaxial cyclic loading unloading compression test was adopted to study the mechanical behavior of granite specimens after thermal treatment by experiment and numerical simulation. The stress-strain curves, elastic modulus, Poisson's ratio, plastic strain, energy and AE characteristic was analyzed, and the effect of temperature and confining on the damage evolution was investigated. The following conclusion are obtained:

(1) On the one hand, the strain energy release gradually after several cycles under cyclic loading compression, and the damage degree is lesser than that under monotonic loading. On the other hand, the failure modes under triaxial cyclic loading are more complicated than that under triaxial monotonic loading, which make the shear plane rougher. Therefore, the residual strength is higher than that under monotonic loading.

(2) After $600^{\circ} \mathrm{C}$ thermal treatment, the bearing structure of specimen is destroyed by high temperature, micro-crack continuously increases under unloading and loading process. Therefore, the peak strength of specimen under uniaxial cyclic loading is lesser than that under monotonic loading.

(3) Elastic modulus first increases and enter a stable phase, then decreases before becoming constant again with cycle number. Applied confining pressure make the increasing stage shorter, and high temperature treatment make the elastic modulus more sensitive to confining pressure. Poisson's ratio remains near constant in the initial stage, then increases rapidly, and decreases slightly before entering a stable phase again with cycle number on the whole. However, the initial constant stage disappear when $T=600^{\circ} \mathrm{C}$.

(4) Axial plastic strain non-linearly increases with the maximum axial strain on a concave type, whereas the non-linear characteristic decreases when $T=600^{\circ} \mathrm{C}$. It means that damage occurred once applied compression, and it can be verified by AE characteristic. Radial strain even appear compressive characteristic in the initial stage, which indicates that the grain adjust under triaxial cyclic loading-unloading compression. And, the compressive characteristic is more obvious with increasing temperature and decreasing confining pressure.

(5) The radial input and elastic strain energy is relatively small compared with axial input energy, axial elastic strain energy and dissipated energy. When $T=25$ and $300^{\circ} \mathrm{C}$, axial input energy mainly transfer as axial strain energy at initial loading stage, whereas axial strain energy and dissipated energy are near equal when $T=600^{\circ} \mathrm{C}$. Confining pressure increases the carrying capacity of rock, and need more dissipated energy to destroy the rock. Therefore, when the specimen failed, the dissipated energy increases with the increase of confining pressure. Confining pressure also restrain the crack initiation and propagation, therefore the variation of dissipated energy of specimen with confining is irregular before failure.

These observations indicate that changes in mechanical of granite are impacted significantly by thermal treatment and these effects must be accommodated in performance assessment. 


\section{Acknowledgements}

The research was supported by the Fundamental Research Funds for the Central Universities (2015XKZD05).

\section{Compliance with Ethical Standards}

Conflict of interest: The authors declare no conflict of interests

\section{References}

Arora K, Chakraborty T, Rao KS (2019) Experimental study on stiffness degradation of rock under uniaxial cyclic sinusoidal compression loading. Rock Mechanics and Rock Engineering 52(11), 4785-4797.

Bass DJ (1995) Elasticity of minerals, glasses, and melts. In: Ahrens TJ (ed) Mineral physics \& crystallography: a handbook of physical constants. American Geophysical Union, Washington, D. C., pp 45-63.

Carpenter M A, Salje E K H, Graeme-Barber A (1998) Spontaneous Strain as a Determinant of Thermodynamic Properties for Phase Transitions in Minerals. Eur. J. Miner. 10:621-691.

Chen S, Yang C, Wang G (2017) Evolution of thermal damage and permeability of Beishan granite. Applied Thermal Engineering 110: 1533-1542.

Eberhardt E, Stead D, Stimpson B (1999) Quantifying progressive pre-peak brittle fracture damage in rock during uniaxial compression. International Journal of Rock Mechanics and Mining Sciences, 36(3):361-380.

Fan J, Jiang D, Liu W, Wu F, Chen J, Daemen JJK (2019) Discontinuous fatigued of salt rock with low-stress intervals. International Journal of Rock Mechanics and Mining Sciences 115, 77-86.

Fei, Y. Thermal expansion. In Mineral Physics and Crystallography: A Handbook of Physical Constants; American Geophysical Union: Washington, DC, USA, 1995; pp. 29-44.

Ghazvinian E, Diederichs MS (2018) Progress of brittle microfracturing in crystalline rocks under cyclic loading conditions. Journal of the Southern African Institute of Mining and Metallurgy 118(3), 217-226.

He M, Li N, Zhu C, Chen Y, Wu H (2019) Experimental investigation and damage modeling of salt rock subjected to fatigued loading. International Journal of Rock Mechanics and Mining Sciences 114, 17-23.

Jiang C, Duan M, Yin G, Wang JG, Lu T, Xu J (2017) Experimental study on seepage properties, ae characteristics and energy dissipation of coal under tiered cyclic loading. Eng Geol 221:114-123.

Kaiser J (1953) Erkenntnisse und Folgerungen aus der Messung von Gerauschen bei Zugbeanspruchung von metallischen Werkstoffen. Archiv fur das Eisenhuttenwesen 24(1-2): 43-45.

Li C, Nordlund E (1993) Assessment of damage in rock using the Kaiser efect of acoustic emission. Int J Rock Mech Min Sci \& Geomech Abstr 30:943-946.

Liu E, He S (2012) Effects of cyclic dynamic loading on the mechanical properties of intact rock samples under confining pressure conditions. Engineering Geology 125, 81-91.

Meng QB, Zhang MW, Han LJ, Pu H, Nie TY (2016) Effects of acoustic emission and energy evolution of rock specimens under the uniaxial cyclic loading and unloading compression. Rock Mech Rock Eng 49(10):3873-3886.

Meng QB, Zhang MW, Han LJ, Pu H, Chen YL (2018) Acoustic emission characteristics of red sandstone specimens under uniaxial cyclic loading and unloading compression. Rock Mech Rock Eng 51(4):969-988.

Momeni A, Karakus M, Khanlari GR, Heidari M (2015) Effects of cyclic loading on the mechanical properties of a granite. International Journal of Rock Mechanics and Mining Sciences 100(77), 89-96.

Peng J, Wong L N Y, Teh C I, Li Z H (2018) Modeling Micro-cracking Behavior of Bukit Timah Granite Using Grain-Based Model. Rock Mechanics \& Rock Engineering 51:135-154. 
Peng K, Zhou J, Zou Q, Zhang J, Wu F (2019) Effects of stress lower limit during cyclic loading and unloading on deformation characteristics of sandstones. Construction and Building Materials 217, 202-215.

Rao MVMS, Ramana YV (1992) A study of progressive failure of rock under cyclic loading by ultrasonic and AE monitoring techniques. Rock Mech Rock Eng 25:237-251.

Tian W L, Yang S Q, Huang Y H (2018) Macro and micro mechanics behavior of granite after heat treatment by cluster model in particle flow code. Acta Mechanica Sinica 34(01):175-186.

Wang P, Yin T, Li X, Zhang S, Bai L (2019) Dynamic properties of thermally treated granite subjected to cyclic impact loading. Rock Mechanics and Rock Engineering 52(4), 991-1010.

Wang Z, Li S, Qiao L, Zhang Q (2015) Finite element analysis of the hydro-mechanical behavior of an underground crude oil storage facility in granite subject to cyclic loading during operation. International Journal of Rock Mechanics and Mining Sciences 73, 70-81.

Wang Z, Yao J, Tian N, Zheng J, Gao P (2018) Mechanical behavior and damage evolution for granite subjected to cyclic loading. Advances in Materials Science and Engineering, 2018.

Wittels, M. (1951). Structural transformations in amphiboles at elevated temperatures. American Mineralogist: Journal of Earth and Planetary Materials 36(11-12):851-858.

Xie HP, Ju Y, Li LY (2005). Criteria for strength and structural failure of rocks based on energy dissipation and energy release principles. Chin J Rock Mech Eng. 24 (17):3003-3010. (in Chinese)

Xiong L, Wu S, Zhang S (2019) Mechanical Behavior of a Granite from Wuyi Mountain: Insights from Strain-Based Approaches. Rock Mechanics and Rock Engineering 52(3), 719-736.

Yang SQ, Ranjith PG, Huang YH, Yin PF, Jing HW, Gui YL, Yu QL (2015) Experimental investigation on mechanical damage characteristics of sandstone under triaxial cyclic loading. Geophysical Journal International 201(2), 662-682.

Yang SQ, Tian WL, Ranjith PG (2017a) Experimental Investigation on Deformation Failure Characteristics of Crystalline Marble Under Triaxial Cyclic Loading. Rock Mech Rock Eng 50:2871-2889.

Yang SQ, Ranjit, PG, Jing HW, Tian WL, Ju Y (2017b) An experimental investigation on thermal damage and failure mechanical behavior of granite after exposure to different high temperature treatments. Geothermics 65: 180-197.

Ye DY, Wang ZL. (2001) A new approach to low-cycle fatigued damage based on exhaustion of static toughness and dissipation of cyclic plastic strain energy during fatigued. International Journal of Fatigued 23(8) 679-687.

Zhou HW, Wang ZH, Wang CS, Liu JF (2019) On acoustic emission and post-peak energy evolution in Beishan granite under cyclic loading. Rock Mechanics and Rock Engineering 52(1), 283-288.

Zhou KP, Liu TY, Hu ZX (2018) Exploration of damage evolution in marble due to lateral unloading using nuclear magnetic resonance. Eng Geol 244: 75-85.

Zhao XG, Cai M, Wang J, Li PF (2015) Strength comparison between cylindrical and prism specimens of Beishan granite under uniaxial compression. International Journal of Rock Mechanics and Mining Sciences (76): 10-17.

Zhao Y S, Meng Q R, Kang T L, Xi B P (2008) Micro-CT experimental technology and micro-investigation on thermal fracturing characteristics of granite. Chin. J. Rock Mech. Eng. 27:28-34. (in Chinese)

Zhao Z H (2016) Thermal influence on mechanics properties of granite: a microcracking perspective. Rock Mech. Rock Eng. 49:747-762.

\section{Hosted file}


Cyclic_Loading-unloading-Figures-Table.docx available at https://authorea.com/users/349416/ articles/474444-failure-behavior-of-the-thermal-treated-granite-under-triaxial-cyclicloading-unloading-compression 